\title{
PRIMEROS PASOS DEL CONSTITUCIONALISMO COLOMBIANO 1810-1815 LAS CONSTITUCIONES PROVINCIALES.
}

\author{
FIRST STEPS ON COLOMBIAN \\ CONSTITUCIONALISM 1810-1815 \\ PROVINCIAL CONSTITUTIONS.
}

\author{
Wilman Amaya León \\ Universidad Libre - \\ Colombia
}

\begin{abstract}
SUMARIO: I. ANTECEDENTES DEL PROCESO DE FORMACION CONSTITUCIONAL COLOMBIANO.- 1.1. conformación de juntas provinciales de gobierno.- 1.2. declaraciones de independencia.- II. CONSTITUCIONES PROVINCIALES PROMULGADAS EN LA NUEVA GRANADA ENTRE 1810-1815.- 2.1 Constitución de la Provincia del Socorro.- 2.2 Constitución de la Provincia de Cundinamarca. - 2.3. Constitución de la Provincia de Tunja.- 2.4 Constitución de la Provincia de Antioquia.- 2.5. Constitución del Estado de Cartagena.- 2.6. Constitución para la Provincia de Popayán.- 2.7. Constitución del Estado libre de Neiva.- 2.8. Reglamento para el gobierno de la Provincia de Pamplona.- 2.9. Constitución de la Provincia de mariquita.
\end{abstract}

Resumen: El proceso de formación constitucional en los estados modernos tuvo dentro de sus características propias el hecho de ser diferente entre uno y otro Estado. Por más vecinos que fueran, siguieron una senda constitucional distinta; uno fue el derrotero seguido por los ingleses, otro el de los franceses y lógicamente en nada habría de parecerse el de las colonias de Norteamérica. La Nueva Granada no fue la excepción, su proceso constitucional fue distinto a los demás, tras romper los nexos que los unían a la madre patria los neogranadinos siguieron rutas distintas; cada provincia del Virreynato adoptó medidas diversas a las tomadas por las demás, ninguna siguió los lineamientos de la junta que quiso ser suprema en Santafé, al contrario se opusieron a las determinaciones que se tomaron en la Capital ante las marcadas diferencias regionales y las distancias que para la época se acentuaban por la falta de caminos adecuados.

Estas circunstancias marcaron el sendero de formación constitucional en la antigua Nueva Granda hoy República de Colombia, en sus inicios la idea de república o de una nación unida estuvo muy distante; al contrario, cada provincia se organizó como bien dispuso, permitiendo de esta manera que aparecieran en el universo regional, un grupo de constituciones provinciales que fueron el origen del constitucionalismo colombiano y que habría de convertirse en su sello particular. 
Abstract: The constitutional formation process in modern states had within its own characteristics the fact that it was different from one state to another. No matter how many neighbors they were, they followed a different constitutional path; one was the course followed by the English, another was that of the French, and logically it would not resemble that of the North American colonies. New Granada was not the exception, its constitutional process was different from the others, after breaking the ties that united them to the mother country, the New Granadans followed different routes; Each province of Virreynato adopted measures different from those taken by the others, none followed the guidelines of the Board that wanted to be supreme in Santafé, on the contrary, they opposed the determinations that were taken in the Capital; the marked regional differences and the distances that for the time were accentuated by the lack of adequate roads.

These circumstances marked the path of constitutional formation in the old Nueva Granda, today the Republic of Colombia, in its beginnings the idea of a republic or of a united nation was very distant; On the contrary, each Province was organized as it had well arranged, thus allowing a group of provincial constitutions to appear in the regional universe, which were the origin of Colombian Constitutionalism and which would become its particular seal.

Palabras clave: Nueva Granada, Colombia, Constitución, España, Virreynato, Provincias.

Key Words: Nueva Granada, Colombia, Constitution, Spain, Viceroyalty, Provinces.

\section{ANTECEDENTES DEL PROCESO DE FORMACION CONSTITUCIONAL COLOMBIANO.}

Antes de iniciar el estudio de las constituciones provinciales promulgadas en la Nueva Granada en el periodo de 1810 a 1815 , es necesario analizar los hechos que sirvieron de punta de lanza para este proceso de formación constitucional neogranadino, al respecto los tratadistas coinciden en que hubo algunos eventos externos sucedidos en el siglo XVIII que influyeron en el pensamiento de los neogranadinos a comienzos del siglo XIX.

En primera instancia tenemos las ideas de la ilustración, en especial el pensamiento del liberalismo politico postulado por Hobbes, Locke, Rousseau, Voltaire, Diderot, Montesquieu, entre otros, quienes desde Inglaterra y Francia movieron los cimientos del antiguo régimen al proponer sus tesis en contra del absolutismo monárquico promulgando ideas como soberanía popular, división de poderes en el estado, igualdad de derechos entre los ciudadanos y participación de todos en el gobierno.

En segundo lugar, están las dos grandes revoluciones del siglo XVIII: El movimiento independentista de los Colonos de Norteamérica en contra de la Corona de Inglaterra y la revolución de los franceses, eventos que sin lugar a dudas cambiaron el orden constitucional en esas naciones y que 
de una manera u otra impactaron el proceso de las nacientes repúblicas de América del Sur.

También hay unidad de criterios, al señalar algunos hechos que se presentaron al interior del Virreinato y que a la postre influyeron en el proceso de formación constitucional en la Nueva Granada: El levantamiento del Común de 1780 a 1783 fue el evento del siglo XVIII que dejó sembradas las semillas de la inconformidad en el corazón de criollos, plebeyos y una generación de neogranadinos que a comienzos del siglo XIX gestaron la conformación de las Juntas Provinciales de Gobierno, quienes nacieron justo cuando el movimiento comunero estaba en su apogeo o que fueron hijos de algunos de sus actores principales.

No obstante, el hecho que más influyó en el proceso de formación constitucional neogranadino, se presentó en Europa a comienzo del siglo XIX cuando la península Ibérica fue invadida por las tropas de Napoleón Bonaparte quien tomó el control de Portugal y España con la consecuente abdicación al trono de los Borbón. Este fue sin lugar a dudas, el evento que despertó en primera instancia en los habitantes del Virreynato de la Nueva Granada, un sentimiento nacionalista en favor de la Corona española, para luego desencadenar en algunos intentos independentistas. Dos sucesos se desprendieron de esta invasión, la conformación de las Juntas Provinciales de Gobierno y las declaraciones independentistas, los cuales, por su importancia en el proceso de formación constitucional, serán estudiados a continuación:

\subsection{Conformación de las Juntas Provinciales de Gobierno}

Al tomar el control de la península Ibérica, Napoleón designó como Rey de España a su hermano José, tras haber logrado la abdicación en su favor de Carlos IV de Borbón; el rechazo de los españoles a la invasión fue total, su oposición férrea despertó un sentimiento nacionalista sin antecedentes, que los motivó a organizarse para la expulsión de los invasores, defender su territorio y regresar a los Borbón al trono español. Con este fin, cada una de las provincias españolas conformó sus Juntas de Gobierno, por medio de las cuales pudieron dirigir sus destinos, controlar el orden público interno y gobernar su territorio en nombre de su Rey Fernando VII, hasta unificarse posteriormente en la Junta de Sevilla que se consolidó como Junta Suprema Central Gubernativa del Reino de España e Indias desde el 25 de septiembre de 1808.1

Desde el momento mismo de su conformación, los Diputados de la Junta Suprema de España, comprendieron, que, para lograr sus objetivos, en especial el de expulsar de su territorio a las tropas francesas y regresar al trono de España a los Borbón, debían convocar a la unidad nacional en torno suyo, incluyendo no solo a las provincias de la península, sino también a los Virreinatos españoles en la América Hispana.

Esta circunstancia generó un cambio brusco en la política interior de España; en las actas se leen los siguientes apartes invitando a las colonias a

${ }^{1}$ Sánchez Manuel Segundo. Documentos para la historia de la Provincia de Cartagena de Indias. Imprenta de Medardo Rivas, Bogotá, 1883, Pp 27 
unirse a la Junta Suprema en defensa de la causa de su Rey Fernando VII: "Las américas tan leales a su Rey como la España europea, no pueden dejar de unirse a ella en causa tan justa, uno mismo será el esfuerzo de ambas por su Rey, por sus leyes, por su patria y por su religión". En esta ocasión, las ideas igualitarias nacidas en Bayona, que habian sido rechazadas en un comienzo por los peninsulares, fueron retomadas al señalar:

"Somos españoles todos. Seámoslo, pues, verdaderamente reunidos en defensa de la religión, del Rey y de la patria."2

Estas manifestaciones no quedaron solo en deseos, los americanos españoles fueron convocados para enviar sus diputados a los distintos entes de gobierno, en el texto de la Real orden del 22 de enero de 1809 expedida por la Junta Central Gubernativa del Reino, se estableció: "Los Reinos, Provincias e Islas que conforman los referidos dominios, deben tener representación nacional e inmediata a su real persona y constituir parte de la Junta Central Gubernativa del Reino, por medio de sus correspondientes Diputados." 3 En estos términos, la junta confirió a los americanos representación por medio de sus diputados y les reconoció su condición de "españoles".

E1 29 de enero de 1810, es creado el Consejo de Regencia para reemplazar la Junta Suprema y gobernar en nombre del Rey Fernando VII, este organismo continuó con la politica asumida por la junta cual fue unir toda España y lograr la fidelidad de los neogranadinos, por lo que expidió su proclama del 14 de febrero de 1810 en la cual señalo: "Desde este momento Españoles Americanos, os veis elevados a la dignidad de hombres libres: no sois ya los mismos que antes, encorvados bajo un yugo mucho más duro..."4 Posteriormente, el 28 de febrero de 1810, la Junta superior de Cádiz ratifico su llamado al decir: "Cádiz os habla pueblos de América y confia que sus voces serán oídas de esos paises con la adhesión y fraternidad que se deben a los vinculos estrechos que la unen con vosotros".

Los primeros pasos para la independencia de las colonias americanas de España ya se habian dado y fueron justo en el mismo territorio peninsular, ante la inminente necesidad de la unidad nacional en España, la Junta Suprema de Sevilla y luego el Consejo de Regencia reconocieron igualdad jurídica a las provincias de uno y otro continente lo que implicaba entre otros asuntos, igualdad de derechos a peninsulares y americanos, tal como había quedado plasmado en el Estatuto de Bayona.

Esta circunstancia, fue la oportunidad que los criollos estaban esperando, cada provincia diseñó el plan para conformar su Junta de Gobierno siguiendo el modelo de las provincias españolas, los cabildos,

\footnotetext{
2 Sánchez Manuel Segundo. Documentos para la historia de la Provincia de Cartagena de Indias, op cit, $\mathrm{Pp} 6$.

3 Sánchez Manuel Segundo. Documentos para la historia de la Provincia de Cartagena de Indias, op cit, $\mathrm{Pp} 16$.

4 Sánchez Manuel Segundo. Documentos para la historia de la Provincia de Cartagena de Indias, op cit, $\mathrm{Pp} 39$.
} 
tomaron la iniciativa haciendo el llamado a sus vecinos para la conformación de las Juntas de Gobierno. Los movimientos más importantes en los cuales se conformaron juntas provinciales de gobierno fueron en su orden:

Capitanía de Quito, 10 de agosto de 1809.

Capitanía de Caracas, 19 de abril de 1810.

Villa de Nuestra Señora del Socorro, 10 de julio de 1810.

Ciudad de Santafé, 20 de julio de 1810.

Provincia de Neiva, 27 de julio de 1810.

Provincia de Pamplona 31 de julio de 1810.

Provincia de Tunja, 26 de julio de 1810.

Provincia de Santa Marta, 10 de agosto de 1810.

Provincia de Popayán, agosto 11 de 1810.

Provincia de Cartagena, 13 de agosto de 1810.

Provincia de Antioquia, 22 septiembre de 1810.

\subsection{Declaraciones de independencia (1811 - 1813)}

El año de 1810 se despidió de la Nueva Granada en medio de un caos absoluto; quedando los criollos al frente de las juntas Provinciales de Gobierno, quienes inexpertos en estas lides burocráticas trataban de organizar sus provincias como mejor les parecía, las derrocadas autoridades peninsulares tomaron rumbo a España y algunos funcionarios de la Corona quedaron detenidos en los calabozos de las provincias; en medio de las celebraciones que este logro significó para los neogranadinos, al interior de las juntas provinciales se iniciaron los arreglos burocráticos para designar los funcionarios que habrian de reemplazar a los Oficiales Reales en los distintos cargos, empezando además, el estudio de la forma de gobierno que cada provincia habría de adoptar, sin lograr la unión federativa propuesta desde un inicio por la junta de Santafé.

El control que en un comienzo tenian los cabildantes leales a la Corona española en la Juntas Provinciales de Gobierno, empezó a ser reemplazado por algunos neogranadinos afectos a las ideas independentistas, quienes impulsados por dos circunstancias precipitaron el proceso de separación de la Nueva Granada: Por una parte, el Consejo de Regencia, desconoció la autoridad de las Juntas Provinciales de Gobierno, nombrando nuevos funcionarios peninsulares para reemplazar los depuestos por ellas, empezando por el Virrey de Santafé y los Capitanes Generales de Caracas y Quito y por la otra se desató la rivalidad entre las provincias neogranadinas en especial las que no aceptaban el liderazgo de Santafé.

Así como la conformación de las Juntas Provinciales de Gobierno se fue dando de manera aislada y sin aceptar el liderazgo de Santafé, igual fenómeno se dio con las declaraciones de independencia, inicialmente dos provincias tomaron la determinación de no reconocer la autoridad del Consejo de regencia de España:

El primer pronunciamiento lo hizo la junta de Santafé el 26 de julio de 1810, al votar de forma unánime romper el juramento de lealtad hecho el 
20 de julio al Consejo de Regencia de España, poniendo fin a la subordinación a esta institución o a cualquier otro cuerpo o persona que en defecto de la de su legítimo soberano el Señor Don Fernando VII, no sea proclamado por el voto libre y general de la nación. ${ }^{5}$

Días después la Provincia del Socorro desconoció la autoridad del Consejo de Regencia el 15 de agosto de 1810, al promulgar su Constitución, en la cual estableció: "No habiendo reconocido la provincia del Socorro al Consejo de Regencia, hallándose ausente su legitimo Soberano el señor don Fernando Séptimo y no habiendo formado Un cuerpo Nacional Compuesto de igual número de vocales de cada provincia para que conozca sobre los grandes intereses del cuerpo social, que son los de paz y guerra, reasume por ahora todos esos derechos."6

El primer intento de unión entre algunas provincias que dio resultados favorables, fue el de las Confederaciones, los diputados aprovecharon esta intención federativa para conformarlas. La importancia de estas Confederaciones radicó en que se convirtieron en el instrumento de unión entre las Provincias, pero además porque fue al interior de ellas en que se determinó romper de plano los lazos de unión con la Corona de España y de esta manera hacer las primeras manifestaciones verdaderamente independentistas de la Nueva Granada.

El honor de haber dado la primera declaración formal de independencia, corresponde a la Confederación Americana de Venezuela, reunida el día 5 de julio de 1811, congregando las Provincias de Caracas, Cumaná, Barinas, Margarita, Barcelona, Mérida y Trujillo, en la cual tajantemente manifestó: "declaramos solemnemente al mundo que sus Provincias Unidas son, y deben ser desde hoy, de hecho $y$ de derecho, Estados libres, soberanos $e$ independientes y que están absueltos de toda sumisión y dependencia de la Corona de España o de los que se dicen o dijeren sus apoderados o representantes, y que como tal Estado libre $e$ independiente tiene un pleno poder para darse la forma de gobierno que sea conforme a la voluntad general de sus pueblos, declarar la guerra, hacer la paz, formar alianzas, arreglar tratados de comercio, limite y navegación, hacer y ejecutar todos los demás actos que hacen y ejecutan las naciones libres e independientes."

En virtud de esta declaración, los venezolanos, buscaron romper de una vez por todas el vínculo de unión que los ataba a la madre patria, la cual: "en uso de los imprescriptibles derechos que tienen los pueblos para destruir todo pacto, convenio o asociación que no llena los fines para que fueron instituidos los gobiernos, creemos que no podemos ni debemos conservar los lazos que nos ligaban al gobierno de España, y que, como todos los pueblos del mundo, estamos libres y autorizados para no depender de otra autoridad que la nuestra".

Este ejemplo fue seguido por la Confederación de las Provincias Unidas de la Nueva Granada, que congregó las Provincias de Antioquia, Cartagena, Neiva,

\footnotetext{
${ }^{5}$ colección bicentenario. Actas de formación de juntas y declaraciones de independencia. Bucaramanga 2008. Pp. 34.

${ }^{6}$ Amaya León Wilman. Constitución de la Provincia del Socorro. Ed. Universidad Libre, Socoro 2016Pp. 85.

7 Biblioteca Virtual Miguel de Cervantes. Actas de la independencia de Venezuela. Caracas 2003. Pp. 34.
} 
Pamplona y Tunja, en su acta de fecha 27 noviembre de 1811 el artículo quinto señaló: "Todas y cada una de las provincias unidas, y que en adelante se unieren de la Nueva Granada, o de otros estados vecinos, desconocen expresamente la autoridad del poder ejecutivo o Regencia de España, Cortez de Cádiz, Tribunales de justicia y cualquier otra autoridad subrogada o substituida por las actuales o por los pueblos de la peninsula"8

El acta de la Confederación Neogranadina, fue un documento más complejo, en sus setenta y ocho artículos reunió todo un conjunto normativo constitutivo del pacto de federación de las cinco provincias que lo suscribieron, las cuales se reconocieron mutuamente como iguales, independientes y soberanas, unidas por la más firme amistad y alianza, ligadas con un pacto eterno, acordando conformar un Congreso de las Provincias Unidas, depositario de la soberanía, sin sacrificar la independencia de cada provincia. Este pacto no fue suscrito por los diputados de Cundinamarca y Chocó, al considerar que el sistema federativo era inconveniente.

En la Real Audiencia de Quito, luego de los lamentables sucesos con que se suprimió la primera Junta de Gobierno en 1809, en los cuales el Virrey de Santafé impuso su autoridad por las armas a comienzos de agosto de 1809. En septiembre de 1810 se constituyó una segunda junta, conformada en nombre de Fernando VII, en las sesiones del mes de octubre y determinó reasumir su soberanía, autoproclamándose como Junta Suprema para consolidar la unión de las provincias de la Real Audiencia de Quito (Cuenca y Guayaquil) y separarse definitivamente de la Junta de Santafé, pero manteniendo su subordinación al Consejo de Regencia de España. ${ }^{9}$

Fue hasta el 11 de diciembre de 1811 , cuando se publicó la declaración independentista de Quito, en la cual se desconoció la autoridad del Consejo de Regencia al señalar: "Decide, declara y sanciona solemne e irrevocablemente, que, desde hoy en adelante, las provincias constituyentes de este reino de Quito, reasumen $y$ mantienen en si mismas $y$ en virtud de legitima representación el ejercicio y administración interna de la soberanía que les corresponde por derecho, quedando absueltas y libres del reconocimiento prestado al Consejo de Regencia y a las Cortes Extraordinarias."10

Luego de estas declaraciones en las confederaciones, las provincias que se consideraban independientes volvieron a liderar los pronunciamientos independentistas, el 11 noviembre 1811 la Provincia de Cartagena en su acta de independencia, manifestó: "La Provincia de Cartagena de Indias es desde hoy de hecho y por derecho Estado libre, soberano e independiente; que se halla absuelta de toda sumisión, vasallaje, obediencia, y de todo otro vínculo de cualquier clase $y$ naturaleza que fuese, que anteriormente la ligase con la corona y gobierno de

\footnotetext{
8 Biblioteca Virtual Miguel de Cervantes. Actas de la independencia de Venezuela. Op cit. Pp. 36.

9 Ceballos Pedro Fermín. Resumen de la historia del Ecuador Tomi III. Imprenta del estado, Lima 1879. Pp 89.
}

10 Morelli Federica, las declaraciones de independencia del Ecuador. Ed. Uniautonoma México 2013, Pp. 55. 
España, y que como tal Estado libre y absolutamente independiente, puede hacer todo lo que hacen y pueden hacer las naciones libres $e$ independientes. Y para mayor firmeza y validez de esta nuestra declaración empeñamos solemnemente nuestras vidas y haciendas, jurando derramar hasta la última gota de nuestra sangre antes que faltar a tan sagrado comprometimiento."11

Cartagena, fue en la Nueva Granada, la provincia que más impulso dio a los movimientos insurreccionales, probablemente por ser la primera en conocer los sucesos de Europa y en especial lo que pasaba en la península Ibérica, pues a ella llegaban las noticias de boca de los marineros y la correspondencia proveniente de Europa y Norteamérica; por ello, sus habitantes conocieron antes que los del interior de la Nueva Granada las ideas liberales, adicionalmente, gracias al comercio desarrollaron un poder económico que los fortaleció frente a las autoridades del Virreinato. Esto explica el porqué, su manifestación independentista fue más allá al romper todos sus vínculos con la Corona y el Gobierno de España, declarándose como Estado libre e independiente.

Su ejemplo fue seguido por la Provincia de Tunja, la cual, tras reunir los diputados provinciales y parroquiales para definir su nueva forma de gobierno, el 9 de diciembre de 1811, promulgaron su constitución incluyendo la declaratoria en el capítulo tercero: "La Provincia de Tunja se declara independiente de toda autoridad civil de España y de cualquiera otra nación, Pero sujetándose sobre este punto a lo que se determine en el Congreso General del Nuevo Reyno o de sus provincias unidas."12

Las declaraciones independentistas continuaron el 6 julio 1813, la Provincia de Cundinamarca, con la llegada a la Presidencia del General Antonio Nariño, se decidió por fin a romper los lazos que la unian a España, en su acta expresó: "Nos, los representantes del pueblo de Cundinamarca... Habiendo tomado en consideración el importante punto de si era ya llegado el caso de proclamar solemnemente nuestra absoluta y entera independencia de la Corona y gobierno de España.... Hemos decretado: ...Declaramos y publicamos solemnemente... Que, de hoy en adelante, Cundinamarca es un Estado libre e independiente, que queda separado para siempre de la Corona y gobierno de España y de toda otra autoridad que no emane inmediatamente del pueblo y sus representantes." 13

El caso de la Provincia de Cundinamarca, es el fiel reflejo de las dificultades ideológicas que se presentaron en el Virreynato de la Nueva Granada en el proceso independentista y de formación constitucional, el Cabildo de Santafé conformó el 20 de julio la Junta Suprema de Gobierno, manteniendo su lealtad absoluta al Consejo de Regencia sin desatar los lazos que la unían a España; los debates se dieron inicialmente con el

\footnotetext{
${ }^{11}$ Biblioteca Virtual Luis Ángel Arango. Palabras que nos cambiaron: Lenguaje y poder
} en laindependencia (documentos). Bogotá 2003. Pp. 34.

12 Constitución de la Republica de Tunja año de MDCCCXI. Imprenta de D. Bruno Espinosa, Tunja 1812. Pp. 22.

13 Biblioteca Virtual Miguel de Cervantes. Declaración de independencia de Cundinamarca. Bogotá 2015. 
dominio de los diputados afectos al Rey, los cuales se mantuvieron leales a España inclusive al promulgar la Constitución Monárquica de 1811. Fue necesario esperar hasta la llegada de Don. Antonio Nariño, quien impulso definitivamente su independencia absoluta.

Antes de finalizar el año de 1813, la Provincia de Tunja, ratificó su declaración de independencia el 19 de diciembre, haciendo ver al mundo los dificiles momentos por los que pasaban al manifestar: "Nada es tan notorio como la opresión en que han gemido las colonias que fundaron los españoles a fines del siglo XV y principios del XVI en esta parte del mundo". En la proclama independentista, los Diputados relataron uno a uno los males por los que pasaba la provincia concluyendo que: "A la vista de tales horrores, la única tabla que nos resta para salvarnos es la independencia a que la provincia de Tunja ha aspirado desde que se dio una constitución".

En el texto del acta se lee: "La Provincia de Tunja, declara a la faz del universo, que no reconoce ninguna subordinación al gobierno de la Península, bien sea el que se ha establecido hoy con el nombre de Cortes y Regencia, o cualquier otro que se establezca en la sucesión de los siglos; que sólo reconoce, obedece al Gobierno que ella misma se ha dado para su régimen interior y al General del Congreso de las Provincias Unidas de la Nueva Granada, en lo tocante a los intereses nacionales...".

Una última manifestación independentista en el Virreinato de la Nueva Granada, se dio en el año de 1814 por parte de la Provincia de Neiva el día 8 de agosto, la cual siguiendo el ejemplo de las demás provincias concluyó: "En la ciudad de Neiva, capital de la Provincia libre de su nombre, a 8 de febrero de1814 años, hallándose reunido el Colegio Revisor Electoral, constituyente de ella, por medio de sus diputados y en virtud de los plenos poderes y en la sala destinada para sus acuerdos, dijo: En presencia del Soberano autor de los derechos del hombre y de la justicia de su causa repite y jura que el Estado de Neiva desconoce por Rey a Fernando VII y cualquier otro que se coloque en el trono de España y a toda autoridad que no emane inmediatamente del pueblo o sus apoderados o representantes, rompiendo enteramente la unión politica con la Metrópoli y con su entera separación."14

De esta manera se cierra el ciclo de las declaraciones independentistas de la Nueva Granada, tres confederaciones y cinco provincias rompieron los lasos que las unían a la Corona de España, declarándose unas y otras soberanas y autónomas.

Para una mejor visualización del desarrollo histórico, a continuación, se hace un resumen de la relación por fechas de estas declaraciones independentistas:

26 de julio de 1810:

15 de agosto de 1810:

5 de julio de 1811:

11 noviembre de 1811:
Provincia de Cundinamarca.

Provincia del Socorro.

Confederación Americana de Venezuela.

Provincia de Cartagena.

14 Boletín de historia y antigüedades. Academia colombiana de historia, Bogotá 1902. 
27 noviembre de 1811:

9 de diciembre de 1811:

11 diciembre de 1811 :

6 de julio de 1813:

8 de agosto 1814:
Confederación de las Provincias Unidas de la Nueva Granada.

Provincia de Tunja.

Estado de Quito.

Provincia de Cundinamarca.

Provincia de Neiva.

\section{CONSTITUCIONES PROVINCIALES PROMULGADAS EN LA NUEVA GRANADA ENTRE 1810-1815}

El proceso de formación constitucional neogranadino, inicia en 1810 con la promulgación de la Constitución de la Provincia del Socorro y se extiende hasta 1815 cuando se aprobaron las constituciones de las provincias de Pamplona y Mariquita; esta etapa coincide con la época histórica denominada por algunos como el periodo de la revolución, la patria boba, o como equivocadamente la denominan otros "la primera República" (Sostenemos que equivocadamente, porque si algo no hubo en esa época fue sentimiento de unidad nacional) .

Los primeros pasos no fueron fáciles, los neogranadinos tuvieron que afrontar una lucha ideológica de intereses diversos y una clara rivalidad entre la Junta de Santafé que quiso ser suprema pero jamás llegó a serlo, con provincias como Tunja, Antioquia o Cartagena; en el proceso independentista el tema paso a mayores, Cundinamarca solo recibió la adhesión de dos o tres provincias de las consideradas pequeñas, mientras que la Confederación Neogranadina reunió por su lado a Antioquia, Tunja, Neiva, Pamplona y Mariquita.

En honor a la verdad, debe agregarse que otro grupo de provincias entre las cuales están Riohacha, Santamarta y Panamá, se negaron a aceptar las manifestaciones de independencia, manteniéndose leales a la Corona de España, en definitiva, se puede concluir, que no hubo ningún interés de unión en torno al concepto de nación, por ello hablar de primera república entre 1810 1815 , es una equivocación.

En este proceso de formación de constituciones provinciales, jugó un papel determinante la Confederación Neogranadina, que logró reunir en torno así a las siete más importantes provincias, organizando su Congreso y un modelo federativo acorde con las necesidades de la época, en uno de sus pactos determinó, que cada provincia promulgara su constitución federal, dando a luz de esta alianza siete de las nueve constituciones provinciales (Tunja, Antioquia, Cartagena, Popayán, Neiva, Pamplona y Mariquita).

Las otras dos constituciones provinciales (Socorro y Cundinamarca) que fueron las primeras en ser promulgadas, nacen por fuera de la Confederación Neogranadina, obedecieron a la autonomía de cada territorio y a iniciativa propia sin contar con las demás provincias de la Nueva Granada.

A continuación, se efectuará el análisis de cada una de las constituciones provinciales, siguiendo rigurosamente la fecha de promulgación. 


\subsection{Constitución de la Provincia del Socorro ${ }^{15}$. (15 agosto 1810)}

Una vez conformada y juramentada la Junta Provincial de Gobierno de la Villa de Nuestra Señora del Socorro en sesión del 10 de julio de 1810 aprobó convocar a los cabildos de la ciudad de Vélez y la Villa de San Gil: "para que envien dos diputados con el fin de deliberar sobre el plan y modo de gobierno que deberian establecer".

El encargado de la etapa preparatoria fue Don. José Lorenzo Plata Martínez Alcalde Ordinario de la Villa, quien fue designado por los Diputados presentes como Presidente de la Junta de la Provincial de Gobierno del Socorro, 16 quien ordenó enviar al día siguiente la correspondencia respectiva a los cabildos de la Ciudad de Vélez y la Villa de San Gil, adjuntando a ella, el acta de constitución de la junta y la convocatoria para el día 15 de agosto.

Ese quince de agosto, se reunieron en la Villa del Socorro los delegados de los Cabildos de la Ciudad de Vélez (Dr. José María Durán, Dr. Miguel Angulo y Camacho), de la Villa de San Gil (Dr. José Gabriel Silva, Don. Vicente Romualdo Martínez) y de la Villa del Socorro: (Dr. Pedro Ignacio Fernández, Dr. José Lorenzo Plata Martínez), guiados por el ideario liberal ilustrado que predica: "Es incontestable que a cada pueblo compete por derecho natural determinar la clase de gobierno que más le acomode; también lo es que nadie puede oponerse al ejercicio de este derecho sin violar el más sagrado que es el de la libertad."

Fiel a estos principios, la Junta Provincial de Gobierno de la Provincia del Socorro, promulgó su constitución y "puso por bases fundamentales constitucionales los cánones siguientes":

De la soberanía y el voto popular: La junta ratifica el desconocimiento al Consejo de Regencia señalado en el acta del 10 de Julio, estableciendo además que los representantes del pueblo sean elegidos anualmente por voto popular.

División de poderes: Organiza el poder legislativo en cabeza de la Junta de Representantes, con la facultad de sancionar y promulgar las leyes del nuevo gobierno, dejando el poder ejecutivo a cargo de los Alcaldes Ordinarios.

Libertades individuales: Reconoce la religión cristiana y varios derechos fundamentales entre los cuales se mencionan: Libertad, igualdad, propiedad. Además, reconoce que la tierra es el patrimonio del hombre y que todo hombre vivirá del fruto de su industria y trabajo.

Libertad de comercio y de sus frutos, libertad de industria.

Permite la siembra del tabaco en todo el territorio de la Provincia del Socorro.

15 Amaya León Wilman. Constitución de la Provincia del Socorro. Ed. Universidad Libre, Socoro 2016.

16 Horacio Rodriguez Plata. La provincia del Socorro y la independencia. Bogota, 1963 Pp.60. 
Declara, la igualdad a los indios, dándoles su reconocimiento como ciudadanos de la provincia para gozar de igual libertad y demás beneficios que proporciona a todos la nueva constitución.

Terminan los asistentes jurando solemnemente: "proclamamos nuestra libertad y sancionamos nuestro Gobierno por el acto más solemne y el juramento más santo de ser fieles a nuestra Constitución".

\subsection{Constitución de la Provincia de Cundinamarca ${ }^{17}$ (4 abril 1811)}

En esta fecha fue promulgada la que por muchos años sería considerada como la primera constitución de nuestro país, ante el desconocimiento que existía de la Constitución de la Provincia del Socorro estudiada anteriormente.

Esta es una constitución a la cual los diputados quisieron dar un carácter de monarquía constitucional vitalicia, con un moderando poder del Rey controlado por la Representación Nacional permanente, la cual contenía en su texto algunos elementos republicanos, fue votada por 42 diputados que representaban a las parroquias de la provincia de Cundinamarca, ante la ausencia de los diputados de las demás provincias neogranadinas quienes desde un comienzo se negaron a aceptar la hegemonía de los capitalinos, muestra clara del por qué la Junta de Santafé no fue capaz de consolidarse como la "Suprema".

El texto constitucional inicia ratificando a Fernando VII Rey de España, como Rey legítimo de los cundinamarqueses, para luego reconocer la Religión Católica, Apostólica, Romana como la única y verdadera.

Deja ver entre líneas algunas luces del liberalismo político europeo al dividir los poderes provinciales en Ejecutivo, Legislativo y Judicial, independientes unos de otros; aunque con el derecho de objetar el poder Ejecutivo lo que estime conveniente a las libertades del Legislador en su caso y lugar, el ejercicio del poder Ejecutivo quedó en cabeza del Rey y en ausencia lo asigna al presidente de la Representación Nacional.

El Cuerpo Legislativo, estará dirigido por un Prefecto de la legislatura, un designado para sus ausencias y un secretario; dejando el Poder Judicial a los Tribunales de la provincia.

La Constitución, pone límites claros al abuso del poder al señalar que la reunión de dos o tres funciones de los Poderes, Ejecutivo, Legislativo y Judicial en una misma persona, o corporación, es tiránica y contraria a la felicidad de los pueblos.

Por ello, en ningún caso pueden ejecutarse por un mismo individuo dos o más representaciones distintas en los tres Poderes Ejecutivo, Legislativo y Judicial.

17 E1 texto de la Constitución de la Provincia de Cundinamarca de 1812, se encuentradigitalizado en la Biblioteca digital de la Universidad Nacional

http:/ / bdigital.unal.edu.co/194/61/plan_de_reforma_o_revision_de_la_constitucion.pd f 
La constitución deja en manos del gobierno la garantía para todos sus ciudadanos de la protección de los sagrados derechos de la Religión, propiedad y libertad individual, y la de la imprenta, la seguridad individual y la libertad perfecta en su agricultura, industria y comercio.

El extenso texto constitucional, se compuso de catorce títulos en los cuales reguló:

Título II. De la religión

Título III. De la Corona

Título IV. De la representación nacional

Título V. Del Poder Ejecutivo

Título VI. Del Poder Legislativo

Título VII. Del Poder Judicial

Título VIII. De las elecciones

Título IX. De la fuerza armada

Título X. Del Tesoro nacional

Título XI. De la instrucción pública

Título XII. De los derechos del hombre y del ciudadano

Título XIII. De los deberes del ciudadano

Título XIV. Disposiciones generales

E1 Serenísimo Colegio Constituyente y Electoral de la Provincia de Cundinamarca aprobó esta Constitución, el treinta de marzo de mil ochocientos once, siendo promulgada el cuatro de abril del mismo año.

Meses después, en septiembre de 1811 , se reunió la representación de Cundinamarca, determinando que era necesario revisar la constitución anterior: "Por haberse formado precipitadamente para satisfacer los deseos $e$ instancias de los pueblos que exigian el que con prontitud se les diese alguna."

Así las cosas, el Serenísimo Colegio Revisor Electoral, modificó el 17 de abril de 1812 la constitución cundinamarquesa, quedando así: Cambia el concepto de Provincia a Estado y modifica la forma de gobierno pasando de monarquía constitucional a República, con un gobierno popular representativo, manteniendo la tri-división de poderes en legislativo, ejecutivo y judicial, con preminencia de los derechos del hombre, que pasa al capítulo primero.

Título I. De la religión.

Título II. De la forma de gobierno.

Título III. De la representación nacional.

Título IV. Del poder legislativo.

Título V. Del poder ejecutivo.

Título VI. Del poder judicial.

Título VII. De la residencia.

Título VIII. De la fuerza armada.

Título IX. Del tesoro nacional.

Título X. De la instrucción pública.

Debe agregarse que, a la revisión de esta constitución, asistieron diputados de algunas regiones distintas a Cundinamarca, que en el periodo 
se fueron anexando al Estado, entre otros tenemos: Chiquinquirá, Tocaima, Ibagué, Mariquita, Honda, Armero, Ambalema, El espinal, San gil, Vélez, Socorro.

\subsection{Constitución de la Provincia de Tunja ${ }^{18}$ (9 diciembre 1811)}

El 21 de noviembre de 1811 se reunieron en la capital de la Provincia, los Representantes de los Pueblos de la Provincia de Tunja en asamblea plena: "Con el fin de deliberar sobre la forma de Gobierno que se deba abrazar uniformemente en toda ella, y de fixar las bases de una Constitución que constantemente garantice los derechos del hombre en sociedad." Al termino de las reuniones, el 9 de diciembre de 1811, promulgaron su carta magna.

En el texto de esta constitución y en el nombre de Dios todo poderoso, se encuentra como parte preliminar la declaración de los derechos del hombre en sociedad y los deberes del ciudadano, haciendo énfasis en dos principios fundamentales como lo son el de legalidad y debido proceso, estructurando el marco constitucional en la soberanía popular.

La Constitución de Tunja contempla expresamente en su artículo tercero, la declaración absoluta de independencia de la Provincia respecto de la Corona de España sujetando esta decisión a la voluntad del Congreso General de las Provincias unidas del Nuevo reino de Granada, en una clara manifestación de su espíritu federativo.

La estructura constitucional de esta Provincia, se montó sobre los pilares del liberalismo filosófico norteamericano al adoptar la soberanía popular y un modelo republicano, con una marcada división de poderes en legislativo (bicameral compuesto por Senado y cámara de representantes), ejecutivo (Que tendrá al frente un Presidente Gobernador acompañado por un Teniente Gobernador que supla sus ausencias) y judicial (con un tribunal de jurados y los Alcaldes Ordinarios y Pedáneos).

El esquema del texto constitucional se conforma de cuatro capítulos y diez secciones que regularon la estructura gubernativa de la provincia así.

Capitulo I. De los derechos del hombre en la sociedad.

Capitulo II. Deberes del ciudadano.

Capitulo III. Sobre la independencia.

Capitulo IV. Sobre la forma de gobierno.

Sección 1. Del poder legislativo.

Sección 2. Del poder Ejecutivo.

Sección 3. Del poder judicial.

Sección 4. Del tesoro público.

Sección 5. De la fuerza armada.

Sección 6. Educación pública.

18 E1 texto de la Constitución de la Provincia de Tunja de 1811, se encuentra digitalizado en laBiblioteca digital de la Universidad Nacional.

http://bdigital.unal.edu.co/190/31/constitucion_de_la_republica_de_tunja.pdf 
Sección 7. Congreso electoral.

Sección 8. Representantes para el Congreso General.

Sección 9. Disposiciones generales sobre empleos.

Sección 10. juramentos.

\subsection{Constitución de la Provincia de Antioquia ${ }^{19}$ (3 mayo 1812)}

El Serenísimo Colegio Constituyente y Electoral de la Provincia de Antioquia representado por los diputados de: Medellín, Rionegro, Marinilla y Ciudad de Antioquia, en la muy noble y leal ciudad de Santiago de Armas de Rionegro, el 21 de marzo de 1812 aprobó y sancionó su constitución, la cual fue aprobada por el pueblo el 3 de mayo del mismo año.

La constitución, organiza el gobierno de la provincia como un Estado libre, independiente y soberano, con una marcada de división de poderes pero que reconoce la autoridad del Congreso General de la Nueva Granada o el de las Provincias Unidas, y que está estructurada en diez títulos y tres secciones así:

Título I. preliminares y bases de la constitución.

Título II. De la formación del gobierno.

Título III. Del poder legislativo.

Sección 1. Disposiciones comunes a las dos cámaras.

Sección 2. Del Senado.

Sección 3. De la Cámara de Representantes.

Título IV. Del poder ejecutivo.

Título V. Del poder judicial.

Título VI. De los diputados para el Congreso.

Título VII. Del tesoro común.

Título VIII. De la fuerza armada.

Título IX. Instrucción pública.

Título X. Disposiciones generales.

Tres años después, el diez de julio de 1815, el Gobernador y Capitán General de la Provincia de Antioquia, Don. Dionisio Sánchez de Tejada, comunica a los habitantes de la Provincia, que el Serenísimo Colegio Revisor Constituyente y Electoral sancionó una nueva constitución provincial fundada en el concepto de soberanía popular y la tri división de poderes, en ella se introdujeron algunos cambios sustanciales al texto de 1812, entre los más importantes tenemos:

Reconoce que la Provincia de Antioquia, es parte integrante de la Republica Libre, Soberana e Independiente de la Nueva Granada y que el Congreso de las Provincias Unidas es la autoridad superior de la nación.

19 El texto de la Constitución de la Provincia de Antioquia de 1812, se encuentra digitalizado en la Biblioteca digital de la Universidad Nacional.

http://bdigital.unal.edu.co/191/13/constitucion_del_estado_de_antioquia.pdf 
Asigna las funciones del poder legislativo a una cámara de representantes denominada la Legislatura de Antioquia”, con funciones de tribunal de residencia para todos los miembros de los poderes públicos.

Cambia la denominación del Ejecutivo, la cual queda como Gobernador de la Provincia y designa un Teniente Gobernador, encargado de reemplazarlo cuando fuere necesario.

Reestructura el poder judicial, creando los jueces de primera instancia.

Define la estructura orgánica de las municipalidades, las cuales tendrán dos alcaldes ordinarios, seis regidores y un sindico.

Establece la presencia de dos diputados por la provincia de Antioquia en el Congreso General de la Provincias Unidas, quienes cumplirán funciones por dos años.

Establece la libertad de imprenta.

\subsection{Constitución del Estado de Cartagena ${ }^{20}$ (14 junio 1812)}

Don Manuel Rodríguez Torices, informó a todos los habitantes, que se reunió en Cartagena la Convención Constituyente y Electoral del Estado, compuesta por diputados en representación de los departamentos de: Cartagena, Mompox, San Benito, Tolú y Simiti, aprobando el 14 de junio de 1812 su texto constitucional, en el cual queda expresa la voluntad de la provincia, de unirse a las demás de la Nueva Granada en un cuerpo federativo, bajo los siguientes fundamentos constitucionales.

Título I. De los derechos naturales y sociales del hombre.

Título II. De la forma de gobierno.

Título III. De la religión.

Título IV. De la Convención general de poderes.

Título V. Del poder Ejecutivo.

Título VI. De poder legislativo.

Título VII. De la formación de las leyes y su sanción.

Título VIII. Poder Judicial.

Título IX. De las elecciones.

Título X. De la fuerza armada.

Título XI. Del tesoro público.

Título XII. De la instrucción pública.

Título XIII. Disposiciones varias.

Título XIV. Revisión de la constitución y suspensión de su imperio.

Título XV. Representación del Estado en el Congreso de la Nueva

Granada.

20 El texto de la Constitución del Estado de Cartagena de 1812, se encuentra digitalizado en la Biblioteca digital de la Universidad Nacional.

http:/ / bdigital.unal.edu.co/193/19/constitucion_del_estado_de_cartagena_de_ind ias.pdf 


\subsection{Constitución para la Provincia de Popayán ${ }^{21}$ (17 julio 1814)}

El 17 de julio de 1814, se reunió el Serenísimo colegio constituyente y electoral de Popayán, fecha en la cual sancionó la constitución para la provincia en un texto de 206 artículos organizados así:

Sección primera, Capitulo único: De la religión.

Sección segunda, de los deberes y oficios de la sociedad.

Capitulo primero: De la provincia de Popayán.

Capitulo segundo: Ciudadanos de la provincia y sus derechos.

Capitulo tercero: Del gobierno de la provincia.

Capitulo cuarto: De las elecciones de los representantes municipales.

Capitulo quinto: De la representación provincial.

Capitulo sexto: Tiempo y forma en que debe reunirse la representación.

Capitulo séptimo: Atribuciones de la representación provincial.

Capitulo octavo: Del Senado o tribunal de protección.

Capitulo noveno: Del poder ejecutivo.

Capitulo diez: Del secretario. Capitulo once: Del poder judicial.

Capitulo doce: Disposiciones relativas a los juicios civiles.

Capitulo trece: Disposiciones relativas a los jueces criminales.

Capitulo catorce: De las municipalidades y jueces subalternos.

Capitulo quince: De la fuerza armada.

Capitulo dieciséis: Del tesoro público.

\subsection{Constitución del Estado libre de Neiva22 (31 agosto 1815)}

Reunida la Convención constituyente y electoral en la Ciudad de Neiva, compuesta por diputados de: Neiva, Gigante, Garzón, La plata, Purificación, Yaguará, Paycol y Carnicerías; se estudió y aprobó la constitución que dio vida al Estado de Neiva, ajustada al plan de reforma provisional dictado por el Soberano Cuerpo de la Nación, el 23 de septiembre de 1814 y los decretos del primero y trece de abril de 1815 .

Al haber aceptado la Provincia de Neiva, unirse en un cuerpo federativo a las demás Provincias de la Nueva Granada, adoptando como forma de gobierno la República representativa, con la siguiente estructura constitucional:

21 El texto de la constitución de la Provincia de Popayán 1814, se encuentra digitalizado en la Biblioteca virtual Miguel de Cervantes Saavedra.

http://www.cervantesvirtual.com/portales/constituciones_hispanoamericanas/ob ra- visor/proyecto-de-constitucion-para-la-provincia-de-popayan1814/html/7cce3e08-252a-451b- aab7-a335df6a60d5_2.html\#I_O_

22 E1 texto de la Constitución de la Provincia de Neiva de 1814, se encuentra digitalizado en laBiblioteca virtual del Banco de la Republica.

http://babel.banrepcultural.org/cdm/ref/collection/p17054coll10/id/2237 
Título I. Derechos del hombre en sociedad.

Título II. De la formación del gobierno y sus deberes.

Título III. De la religión.

Título IV. Del poder Ejecutivo.

Título V. De poder legislativo.

Título VI. De poder judicial.

Título VII. De las elecciones.

Título VIII. Del colegio electoral.

Título IX. Representación del Estado en el Congreso de la Nueva

Granada.

Título X. Revisión de la constitución.

\section{8. e Pamplona ${ }^{23}$ (17 mayo 1815)}

En el palacio de la legislatura, fue aprobado el 17 de mayo de 1815, el Reglamento para el gobierno de la Provincia de Pamplona, el cual contiene los cánones constitucionales para estructurar el sistema de gobierno; a tal punto que D. José María Navarro, en su condición de Secretario de Estado señaló: "ordeno, y mando a todos los Tribunales, jefes y autoridades, así civiles, como militares y eclesiásticas, tengan el Reglamento inserto, como Lev fundamental de la Provincia, y que lo obedezcan, y hagan obedecer."

De la forma de gobierno.

Del cuerpo legislativo.

Del poder ejecutivo.

Del poder judiciario.

De la residencia.

De las municipalidades.

Derechos del hombre y del ciudadano.

Soberanía del pueblo.

Derechos del ciudadano.

Deberes del hombre en sociedad.

Deberes del cuerpo social.

Disposiciones generales.

\subsection{Constitución de la Provincia de mariquita ${ }^{24}$ (21 junio 1815)}

El Gobernador y comandante general Don. José León Armero, informó a los habitantes de la Provincia, que, reunida la Serenísima Convención constituyente y electoral de la provincia de Mariquita, conformada por

23 El texto de la constitución de la Provincia de Pamplona 1815, se encuentra digitalizado en la Biblioteca virtual Miguel de Cervantes Saavedra

http://www.cervantesvirtual.com/portales/constituciones_hispanoamericanas/obr a/reglamento- para-el-gobierno-provisorio-de-la-provincia-de-pamplona-17-mayo-de$1815 /$

24 E1 texto de la constitución de la Provincia de Mariquita 1815, se encuentra digitalizado en la Biblioteca virtual Miguel de Cervantes Saavedra

http://www.cervantesvirtual.com/portales/constituciones_hispanoamericanas/obr a/constitucion-politica-del-estado-de-mariquita-1815/ 
diputados de: Honda, La palma, Ambalema, Espinal, Ibagué y Mariquita.

La Provincia de Mariquita, adopto en esta constitución un modelo de Estado autónomo e independiente del español, unido al Congreso de Provincias unidas de la Nueva Granada bajo una forma de gobierno republicana al aprobar y sancionar la constitución provincial con la siguiente estructura:

Título I. Declaración de derechos.

Título II. Derechos del hombre en la sociedad.

Título III. De la religión.

Título IV. Independencia del Estado.

Título V. Forma de Gobierno

Título VI. De la legislatura.

Título VII. Atribuciones de la legislatura.

Título VIII. De la formación de las leyes y su sanción.

Título IX. De la publicación de los actos y reglamentos de la legislatura.

Título X. Del Senado.

Título XI. Del Poder ejecutivo.

Título XII. Del teniente gobernador.

Título XIII. Del supremo poder judicial.

Título XIV. Sala de apelaciones.

Título XV. De la alta corte de suplicas.

Título XVI. De las municipalidades y jueces subalternos.

Título XVII. De los jueces mayores de paz.

Título XVIII. Disposiciones relativas al poder judicial.

Título XIX. Del juicio de residencia.

Título XX. De las elecciones.

Título XXI. Del fomento a la literatura.

Título XXII. De los juramentos.

Titulo XXIII. Disposiciones generales.

Título XXIV. Revisión de la constitución y su imperio.

Título XXV. Representación del estado en el Congreso de la Nueva

Granada.

Así fueron los primeros pasos del constitucionalismo colombiano, su primera etapa se traduce en las "Constituciones provinciales", nueve documentos que permiten conocer a la historia, como cada provincia siguió su camino sin pensar en la verdadera unión de la nación, en esta oportunidad pudieron más los egos de los lideres provinciales que el sentimiento nacionalista, aún faltaba el baño de sangre en la guerra de independencia para que con Bolivar y Santander al mando las provincias comprendieran que solo con la unión se construiría una gran nación.

Enviado el / Submission date:20/02/2021

Aceptado el / Acceptance date: 16/04/2021 